\title{
Autoimmune vasculitis in a child following tetralogy of Fallot repair in Uganda
}

\begin{abstract}
Introduction: Tetralogy of Fallot is one of the conotruncal abnormalities and is the most common cyanotic heart disease worldwide. Conotruncal abnormalities have been closely associated with 22.q.11 deletion syndrome. Children with 22.q.11 deletion syndrome often have thymic hypoplasia, hypocalcaemia and have an increased susceptibility to viral, fungal and bacterial infections due to poor T-cell production. Autoimmune vasculitis has not been well documented among individuals with Tetralogy of Fallot (TOF) though a few reports exist in association with 22.q11.2 deletion syndrome.
\end{abstract}

Case summary: We report a case of an 11 year old child post TOF repair who presented to the Uganda Heart Institute with persistent high grade fevers, abdominal pain, mucosal bleeds and hypocalcaemia, hypokalemia, hypomagnesaemia, thrombocytopenia and elevated acute phase reactants-leukocytosis $(17.9 \times 103)$, neutrophil count $16 \times 103(89 \%)$, elevated C-reactive protein $(80 \mathrm{mg} / 1)$ and elevated immunological tests (C-ANCA, 18U/ml). She improved on intravenous methyl prednisolone.

Conclusion: Children with Tetralogy of Fallot can still manifest with complications such as autoimmune disorders and severe infections given the association with 22q.11 deletion syndrome. Screening for autoimmune abnormalities and electrolytes especially calcium improves on their outcome. We were not able to perform the FISH analysis (for Fluorescent in Situ Hybridization) to confirm the diagnosis of 22q.11.2 deletion syndrome in $\mathrm{KT}$.
Volume 4 Issue 6 - 2017

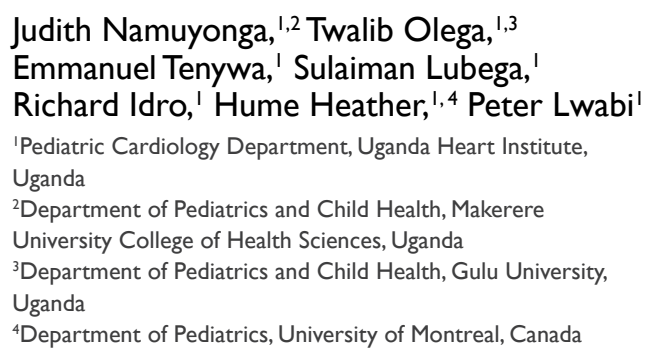

Correspondence: Judith Namuyonga, Uganda Heart Institute, Kampala, Uganda, Tel +25677258088I,

Email jnamuyonga@gmail.com

Received: March 13, 2017 | Published: June 20, 2017

\section{Background}

Tetralogy of Fallot is the most common cyanotic congenital heart disease worldwide. ${ }^{1}$ Among other conotruncal abnormalities, $13-16 \%$ of Tetralogy of Fallot individuals are reported to have 22q11.2 deletion syndrome which is characterized by thymic hypoplasia, endocrine abnormalities and hypocalcaemia. ${ }^{2}$ Individuals with micro deletion 22q11.2 deletion syndrome are prone to auto immune disorders. Defects in thymic development predispose them to impaired immune function especially T cell deficiency. ${ }^{3}$ However autoimmune vasculitis has not been well documented in children with Tetralogy of Fallot. We report on an eleven-year-old child post Tetralogy of Fallot repair who presented with persistent fevers and an over whelming infection.

\section{The case report}

\section{KT}

11-year-old girl had Tetralogy of Fallot (TOF) repair 8years prior to developing the reported illness. She was referred to Uganda Heart Institute from a peripheral clinic with a history of fever and back ache which had been treated as a urinary tract infection with cefalexin then ceftriaxone with no improvement. Four days later, she developed a petichae like rash which was involving the palms and sole of the feet. She also developed bloody diarrhea approximately 9motions in 24hours and abdominal pain. Her previous medical history indicated good health after the TOF repair until a year prior to admission when she developed an acute abdomen which mimicked appendicitis, a skin rash and persistent fevers. She is the last born in the family. Her elder sister suffered a congenital heart disease (ventricular septal defect) that closed spontaneously and her niece had double outlet right ventricle.

\section{Clinical examination}

Revealed a sick child with a fever $39^{\circ} \mathrm{C}$ petichae on palms and soles of the feet Oral thrush and bleeds in the mouth she also had blisters on the lower limbs with secondary infection. She was hypoxic with an oxygen saturation of $86 \%$ on room air. Cardiovascular exam revealed, BP $88 / 56 \mathrm{mmHg}$, grade $3 / 6$ ejection systolic murmur in the left upper sternal area. Abdominal examination revealed had generalized tenderness, no palpable organs. Mentation was good, muscle tone, bulk and power was normal (on admission).

\section{Baseline laboratory results}

upon admission; Full haemogram showed leukocytosis, WBC $17.9 \times 10^{3}$, with differential neutrophil count $16 \times 10^{3}(89 \%)$, Hemoglobin $12.3 \mathrm{~g} / \mathrm{dl}$, thrombocytopenia $93 \times 10^{3}$ and highly elevated C-reactive protein (CRP) of $80 \mathrm{mg} / 1$ (NR $<6 \mathrm{mg} / \mathrm{l})$. The peripheral film revealed macro platelets, left shift and no schistocytes. Electrolytes were deranged (Figure 1).

\section{Hypocalcaemia}

$1.6(2.1-2.5) \mathrm{mEq} / \mathrm{L}$ Hypokalemia $2.6 \mathrm{mmol} / \mathrm{L}$ and hypomagnesaemia $0.6 \mathrm{mEq} / \mathrm{L}$ and the coagulogram;PT/APTT were normal. Blood culture did not grow any organisms; urine analysis revealed yeast cells and cultured $>10^{5}$ Candida albicans.

\section{Cardiac echo}

Showed an intact VSD patch with no residual shunt Good LV systolic function Moderate pulmonary artery conduit stenosis, peak gradient $44 \mathrm{mmHg}$, free pulmonary regurgitation no vegetations 
or thrombi were seen. Fevers escalated despite broad spectrum antibiotics (Piperacillin/Tazobactum), Cefotaxime and Vancomycin.

\section{Day 9 of admission}

KT got drowsy but arousable, developed a stiff neck, positive Kerning's sign, Glasgow coma scale 13/15. She later developed generalized tonic seizures, right sided hemiplegic, and loss of speech. Retinal hemorrhages were seen on fundoscopy. The child was treated with intravenous phonation though she later developed status epileptics which was managed by standard protocol and was later incubated. Cerebral spinal fluid (CSF) was relatively normal, protein 10.3, gram stain, no organisms, HSV $1 \&$ 2PCR negative, CSF cryptococcal antigen (CRAG) negative MTB-PCR negative. Brain Computed Tomography on two separate occasions was normal, thyroid function tests were normal. The C-ANCA was elevated $18(0-2 \mathrm{U} / \mathrm{ml})$, P-ANCA-0.3, normal. With the combined effort of the rheumatologist, pediatrics cardiologists, neurologist and hematologists a diagnosis of autoimmune disease was made basing on the raised C-ANCA. Intravenous methyl prednisolone was given $(1 \mathrm{mg} / \mathrm{kg})$ and Phenytoin $5 \mathrm{mg} / \mathrm{kg} /$ day were given followed by prednisolone $30 \mathrm{mg}$ once a day to be tapered down. KT improved markedly improved, regained consciousness. The C-reactive protein (CRP) dropped to less than $8 \mathrm{mg} / 1$ and the electrolytes were normal, the white cell counts $11.6 \times 10^{3}$, neutrophil count $8.5 \times 10^{3}(73 \%)$, Hemoglobin $8.7 \mathrm{~g} / \mathrm{dl}$. We discharged her in good general condition, able to walk and speak. We employed a multi disciplinary approach in the management of KT including the hematologist, neurologist rheumatologist. A year later, she reported two relapses which manifested with low grade fevers and skin lesions which have been treated with short courses of prednisolone (Figure 2).

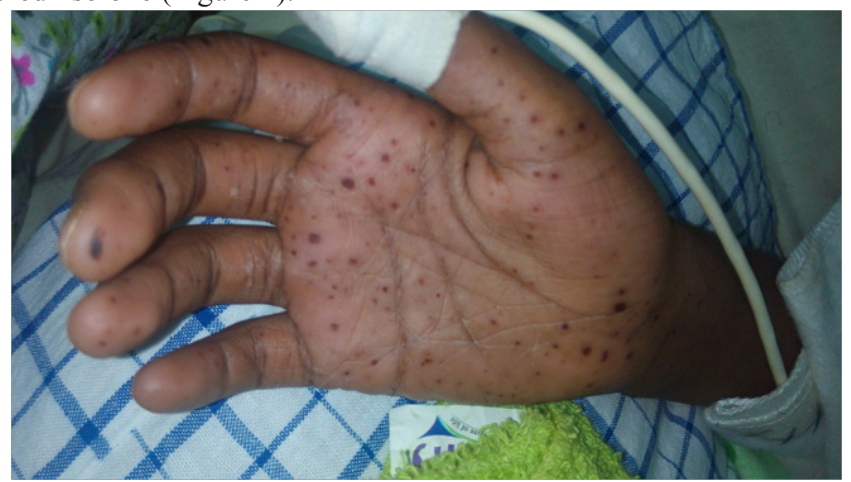

Figure I Lesions in the palms (parental consent and assent were obtained).

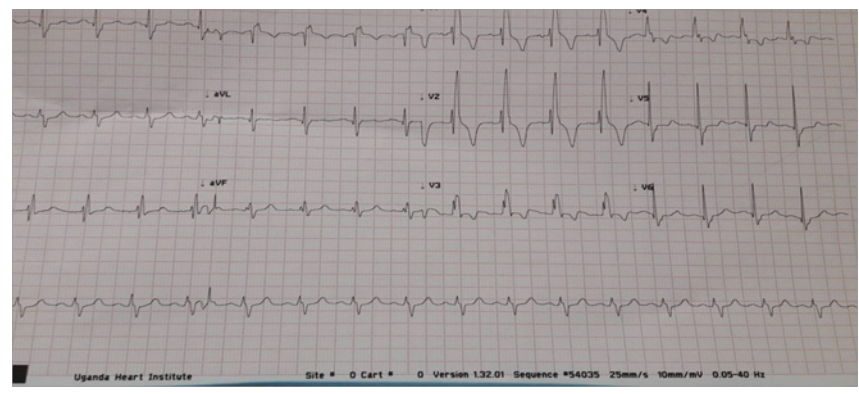

Figure 2 Electrocardiogram showed right axis deviation with right bundle branch block.

\section{Discussion}

Autoimmune vasculitis is a rare complication of Tetralogy of Fallot. Studies have reported autoimmune disease associated with 22q.11.2 deletion syndrome which is commonly found among individuals with conotruncal abnormalities like Tetralogy of Fallot. ${ }^{2}$ With limited ability to perform genetic studies in our setting, the presentation of KT was similar to that commonly seen among individuals with micro deletion 22q11. Hypocalcaemia is often associated with convulsions ${ }^{4}$ and requires supplementation. ${ }^{5}$ Hematologic abnormalities have been reported among individuals with Tetralogy of Fallot especially coagulation derangement. The sufferers tend to have large dysfunctional platelets. ${ }^{6,7} \mathrm{KT}$ had thrombocytopenia and bleeding in the mucous membranes and had large platelets seen on the peripheral film. The thrombocytopenia is often immune related. Patients with Tetralogy of Fallot and Di George syndrome tend to have recurrent infections ${ }^{6}$ just as our patient presented with severe infections including; bacterial infections and fungal infections as evidenced by high neutrophil counts, oral thrush and urine culture for Candida albicans. We performed a septic screen including CRP, and blood culture with a possibility of infective endocarditic which is common among children with cyanotic heart disease. ${ }^{8}$

This diagnosis of autoimmune vasculitis was based on elevated CANCA. Other methods for diagnosing autoimmune disorders include the FISH test which is not readily available in our setting. We noted a drastic improvement in the level of consciousness upon commencing intravenous methyl prednisolone which made the diagnosis of autoimmune disorder very likely. In the routine follow up whether before surgery or post operatively, it is recommended to monitor calcium levels, thyroid function tests, complete blood counts and re assess immunologic tests annually. ${ }^{4} \mathrm{KT}$ had two sick days in the first year of follow-up in which her C-reactive protein was elevated with an associated leukocytosis. She responded to a 3-day course of oral prednisolone.

\section{Conclusion}

Tetralogy of Fallot patients are likely to manifest with challenges in electrolyte regulation especially hypocalcaemia, severe infections and have a high tendencies of autoimmune disorders. Our patient presented with features highly suggestive of deletion 22q11.2 syndrome. Genetic studies would have better informative however these were not available in our setting. A multidisciplinary model is always necessary in the management of these patients.

\section{Acknowledgements}

None.

\section{Conflict of interest}

The author declares no conflict of interest.

\section{References}

1. Tantchou Tchoumi JC, Ambassa JC, Kingue S, et al. Occurrence, aetiology and challenges in the management of congestive heart failure in subSaharan Africa: experience of the cardiac centre in Shisong, cameroon. Pan Afr Med J. 2011;8(1):11.

2. McDonald-McGinn DM, Sullivan KE. Chromosome 22q11.2 deletion syndrome (DiGeorge syndrome/velocardiofacial syndrome). Medicine. 2011;90(1):1-18. 
3. McLean-Tooke A1, Spickett GP, Gennery AR. Immunodeficiency and autoimmunity in 22q11.2 deletion syndrome. Scand J Immunology. 2007;66(1):1-7.

4. McDonald-McGinn DM, Emanuel BS, Zackai EH. 22q11.2 deletion syndrome. Gene Reviews. 1999.

5. Kung SJ, Gripp KW, Stephan MJ, et al. Selective IgM deficiency and 22q11.2 deletion syndrome. Ann Allergy Asthma Immunol. 2007;99(1):8792.
6. Akar NA, Adekile AD. Chromosome 22q11.2 deletion presenting with immune-mediated cytopenias, macrothrombocytopenia and platelet dysfunction. Med Princ Pract. 2007;16(4):318-320.

7. McDonald-McGinn DM, Minugh-Purvis N, Kirschner RE, et al. The 22q11.2 Deletion in African-American patients:an underdiagnosed population? Am J Med Genet A. 2005;134(3):242-246.

8. Gilboa SM, Salemi JL, Nembhard WN, et al. Mortality resulting from congenital heart disease among children and adults in the United States. Circulation. 2010;122(22):2254-2263. 